\title{
BMJ Open Contextual characteristics associated with the perceived neighbourhood scale in a cross-sectional study in a large urban centre in Brazil
}

\author{
Fabiano de Almeida Célio, ${ }^{1}$ Amélia Augusta de Lima Friche, ${ }^{1} \mathrm{M}$ Zane Jennings, ${ }^{2}$ \\ Amanda Cristina de Souza Andrade, ${ }^{1}$ Cesar Coelho Xavier, ${ }^{3}$ Fernando Proietti, ${ }^{3,4}$ \\ Claudia J Coulton, ${ }^{2}$ Waleska Teixeira Caiaffa ${ }^{1}$
}

To cite: de Almeida Célio F, Friche AAdL, Jennings MZ, et al. Contextual characteristics associated with the perceived neighbourhood scale in a crosssectional study in a large urban centre in Brazil. BMJ Open 2018;8:e21445. doi:10.1136/ bmjopen-2017-021445

- Prepublication history for this paper is available online. To view these files, please visit the journal online (http://dx.doi. org/10.1136/bmjopen-2017021445).

Received 5 January 2018 Revised 13 June 2018 Accepted 25 June 2018

\section{Check for updates}

(c) Author(s) (or their employer(s)) 2018. Re-use permitted under CC BY-NC. No commercial re-use. See rights and permissions. Published by BMJ.

${ }^{1}$ Observatory for Urban Health in Belo Horizonte, School of Medicine, Federal University of Minas Gerais, Belo Horizonte, Brazil

${ }^{2}$ School of Applied Social Sciences, Case Western Reserve University Jack Joseph and Morton Mandel School of Applied Social Sciences, Cleveland, Ohio, USA

${ }^{3}$ Faculdade de Saúde e Ecologia Humana, Vespasiano, Brazil ${ }^{4}$ Epidemiology, Centro de Pesquisas René Rachou, Belo Horizonte, Minas Gerais, Brazil

Correspondence to Dr Fabiano de Almeida Célio; maitiz@gmail.com

\section{ABSTRACT}

Introduction Health outcomes have been associated with physical and social characteristics of neighbourhoods, but little is known about the relationship between contextual factors and perceived neighbourhood scale.

Objective To identify the contextual factors associated with self-perceived neighbourhood scale.

Methods We analysed data from a cross-sectional population-based study in Belo Horizonte, Brazil, that took place in 2008-2009. The dependent variable was perceived neighbourhood, encoded as an ordinal scale based on a brief description of the concept of the neighbourhood, and two independent scales relating distance, expressed in terms of geography and time. Street connectivity, demographic density and residents' perceptions of the neighbourhoods' physical and social environment were used as contextual predictors. Individual characteristics were used as covariates. Multilevel ordinal logistic regression models estimated the association between perceived neighbourhood scale and contextual characteristics.

Results Residents that perceive better walkability (OR 2.96; 95\% Cl 1.29 to 3.82) and high amounts of violence (OR 1.35; $95 \% \mathrm{Cl} 1.12$ to 1.62) perceived their neighbourhoods to be larger, even after adjusting for individual characteristics.

Conclusion There are contextual factors that are associated with self-perceived neighbourhood scale. Careful definition of neighbourhood scale is a key factor in improving the results of eco-epidemiological studies. Although these findings must be further explored in other studies, these results can contribute to a better understanding of an appropriate choice of neighbourhood scale, especially for cities in Latin America.

\section{INTRODUCTION}

Eco-epidemiological research has increasingly used the concept of neighbourhood as the geographical area within which physical and social environmental features affect individuals' health outcomes, as part of an emphasis on a more holistic understanding of the factors
Strengths and limitations of this study

Large sample comes from an urban centre in Latin America.

- Analysis includes individual and contextual factors.

- Neighbourhood definition can be obtained by closed-ended questions.

- Analysis could identify contextual factors associated with perceived neighbourhood scale.

- Analysis takes into account physical and social factors of the neighbourhood.

and processes shaping health outcomes within urban areas. ${ }^{1}$

Features in the neighbourhood help explain inequalities in health, can be used in studies aiming to evaluate community interventions intended to improve health outcomes ${ }^{2-4}$ and have been shown to be predictive of health outcomes and health-affecting behaviours, such as cardiovascular diseases, ${ }^{5}$ sexually transmitted diseases, ${ }^{2}$ mental illness ${ }^{6}$ and physical activity, ${ }^{78}$ among others. ${ }^{9-12}$

However, the neighbourhood is a complex concept, and its definitions in epidemiological studies vary widely ${ }^{13}$ and have different methodological approaches. ${ }^{14}$ Chaix et $a l^{13}$ describe two approaches for defining neighbourhood in epidemiological research: the territorial neighbourhood and the ego-centred neighbourhood approaches.

Territorial neighbourhoods are generally administrative areas corresponding to a territory-subdividing approach. However, more complex definitions of territorial neighbourhoods may consider built environment features and population characteristics. Researchers using this approach often select administratively defined, mutually exclusive geographic units, such as census tracts or municipal boundaries, as proxies 
for neighbourhoods. ${ }^{13} 15$ Assuming resident homogeneity, ${ }^{16}$ this approach is adopted because secondary data are often easily available and spatial references are obtainable, which facilitates reproducibility and comparability across studies or over time. However, territorial neighbourhoods consider the same areas for different individuals, and thus, individual differences in neighbourhood experience and exposure cannot be captured under this approach. ${ }^{16}{ }^{17}$ When the same area is attributed to several individuals in a given area, the potential for error is introduced because individuals may not be exposed in a homogeneous way to the physical and social environment of the territory.

The second approach is called ego-centred neighbourhoods and is based on the idea that the contextual factors affecting individuals will differ depending on the actual location and particular geographic circumstances of those individuals. Several techniques can be used to define this approach. Most importantly, the ego-centred neighbourhood results in neighbourhoods that may overlap, are not mutually exclusive and are specific to the household or individual resident. ${ }^{13}$ This approach can be operationalised in three different ways. One uses a buffer, generally a circular area centred on the individual's residence, resulting in neighbourhoods of the same size, though made up of different areas, that may overlap with one another but are not identical. The second approach involves using individual behavioural activity spaces measured by Global Positioning System. This approach captures each individual's movements and activities, creating a unique measure of contextual exposure. ${ }^{918}$ The third method relies on individuals' perceived neighbourhoods.

Perceived neighbourhoods, in turn, can be identified by different strategies. Residents may be asked to identify or draw their neighbourhood on a map, ${ }^{19-22}$ or, alternatively, researchers may ask residents how large they consider their neighbourhood to be or how long it takes to walk from the resident's house to the end of their neighbourhood. ${ }^{13-25}$ This last technique has the advantage of being easily understood by residents and quickly and inexpensively conducted by researchers.

Regardless of the methods, neighbourhood scale needs to be carefully considered. When it is not correctly operationalised and defined, the measures derived can be considered problematic and questionable. Consequently, the understanding of health impacts through the lens of the neighbourhood can be undermined..$^{26}$ One problem that may arise is known in geography as the $\mathrm{e}^{27}$ 'modifiable area unit problem'. Aggregating epidemiological data into differently sized territorial units can yield varying exposure measure results, making it difficult or even impossible to compare findings. Generally, the error of choice of territorial unit of analysis is non-differential, which may underestimate association measures or even not find associations when they do exist. ${ }^{28}$

The attributes that make the neighbourhood of an individual a singular place are commonly characterised by the following qualities: (1) social interaction; (2) social norms and collective effectiveness; (3) institutional resources (schools, health facilities and others); and (4) routine activities within the neighbourhood. As we can see, it is difficult not to incur some kind of neighbourhood boundary definition error when the internal dynamics of the place under study are unknown. ${ }^{29}$

Perceived neighbourhood scale has been found to be related to individual characteristics, such as socioeconomic position, employment, evaluation of the aesthetic aspects, number of relatives living in the same neighbourhood and familiarity with many people in the neighbourhood. ${ }^{25}$ However, the scale of perceived neighbourhood can be influenced by contextual factors such as population density, land use patterns and collective efficacy. ${ }^{19}$ The connectivity of the streets that directly influence the number of routes available to the various points of interest within a neighbourhood can also influence the perception of its size, because connectivity may change the way residents use and circulate in physical space. $^{30}$

This work, by investigating perceived neighbourhood scale, addresses an important methodological question, which concerns the appropriate scale of territorial units of analysis, reducing possible errors inherent to the process of investigating neighbourhood impact on health outcomes. Despite research results indicating a relationship between neighbourhood and health, it is still rare to find studies that measure the influence of contextual factors as shaped by perceived neighbourhood scale. In Latin America, we have not found any studies with this same purpose. Therefore, the objective of this study is to analyse the context attributes associated with the perceived neighbourhood scale in a large urban centre in Brazil.

\section{METHODS}

\section{Data and sample}

The data for this study come from a cross-sectional population-based study called BH Health Study, conducted by the Belo Horizonte Observatory for Urban Health in 2008-2009 and nested in the Federal University of Minas Gerais. The participants of the study were residents belonging to two of the nine sanitary districts of Belo Horizonte: Barreiro and West. These districts were selected because they presented heterogeneity within the city in relation to social, sociodemographic and health indicators. ${ }^{31-33}$

A stratified sample was selected in a three-stage process. To ensure the representation of residents of all socioeconomic levels, the study area was stratified by the health vulnerability index, ${ }^{34}$ a geocoded index created by combining social, demographic, economic and health indicators from different sources for each census tract. At the end of the first and second steps of the sampling process, 149 census tracts and 4048 households were randomly selected. In the third stage, one resident over 
18 years old was randomly selected in each of the identified households. ${ }^{35}$

\section{Dependent variable}

The dependent variable for this study is the perceived neighbourhood scale, which was originally encoded as an ordinal variable with seven options. To obtain the scale, the interviewer read a brief description of the concept of the neighbourhood: 'The neighbourhood is the place where you live and perform routine tasks, such as going to the bakery, grocery store, and local businesses; visiting your neighbours; and walking. The neighbourhood can be understood as the area where you recognize most of the people'. Then, the interviewee was asked, 'Thinking of your neighbourhood, would you describe it as including the following: (1) the houses next door? (2) the block or street you live on? (3) the area within 5 blocks? (4) the area within ten blocks? (5) the area more than ten blocks away? (6) your neighbourhood? (7) your neighbourhood and nearby neighbourhoods?' Subsequently, this variable was recoded, using as reference an additional measure of neighbourhood scale. This measure was a continuous variable obtained from the following question: 'How much time in minutes would you spend walking from the door of your house to the end of what you consider your neighbourhood?' The mean walking time obtained for each of the seven options of the first ordinal question variable was used to collapse the final dependent variable into four options. This procedure was adopted by considering the non-overlapping portion of the $95 \%$ CI between each stratum. Thus, the outcome variable called the perceived neighbourhood scale was recoded into four categories: (1) up to the block or street you live on; (2) within five blocks; (3) within 10 blocks; and (4) more than 10 blocks away.

\section{Contextual predictors}

The independent variables were chosen based on the theoretical (figure 1) model using other studies. ${ }^{425}$ The variables relating to the physical and social environment of the neighbourhood were obtained from domains created by Friche $e$ a $a .^{36}$ Aggregated for each census tract, the domains provide a continuous score ranging from 1 to 4. In this study, we used the following domains: aesthetic quality, walking environment, safety and violence.

The aesthetic quality domain was obtained by asking the participants the following questions about their neighbourhood: (1) Is there trash or litter on the streets and sidewalks?; (2) Is it pleasant for children?; (3) Is it pleasant for young children and adolescents?; (4) Are there trees that make the environment pleasant?

The walking environment domain was obtained by asking the participants the following about their neighbourhood: (1) How do you evaluate public places for sports and leisure?; (2) How do you evaluate the traffic?; (3) Are there stores at a distance you can walk?; (4) Is it easy to walk?; (5) How often do you see other people walking?; (6) How often do you see other people exercising?; (7) Do you feel safe walking during the day?

The violence domain was composed of the following questions: During the past 12 months, did you see or hear about the following: (1) people being mugged in

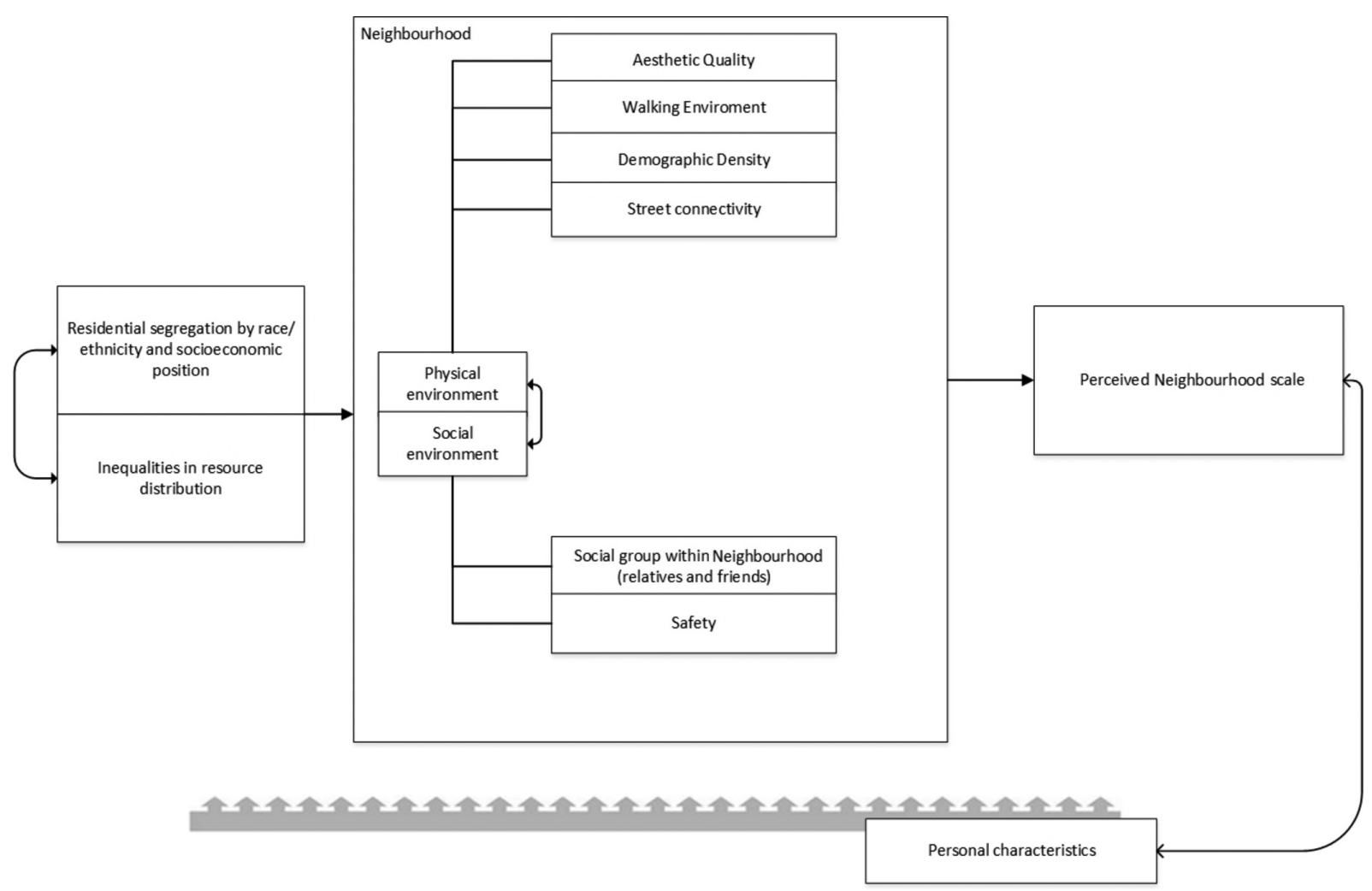

Figure 1 Theoretical model for factors associated with perceived neighbourhood scale. 
the neighbourhood streets?; (2) people fighting using weapons?; (3) people being killed by guns?; (4) people being victims of sexual violence?; (5) women of the neighbourhood being beaten by their husbands and/or partners or relatives?; and (6) children or adolescents of the neighbourhood being assaulted or victims of violence perpetrated by their parents?

The safety domain was built with the following questions: In your neighbourhood, (1) do you feel safe walking during the night?; (2) is violence a problem?

This study also used contextual variables from census tracts and those collected by the city hall for administrative purposes. Street connectivity drawn from all street segments of the area in the study was obtained using Dephmap $^{37}$ (Space Syntax, University of London) software. This software handles the street segment as if it were an axial line and quantifies the segments that intersect each of these lines. ${ }^{30}$ The software delivers a score between zero and nine, where zero represents streets with low connectivity and nine represents highly connected streets. ${ }^{38}$ The final variable was skewed, with a low prevalence of extreme values, so it was recoded into three categories: low connectivity (0 to 3 ), medium connectivity (4) and high connectivity (5 to 9 ).

Population density was calculated for each census tract using data from the 2010 National Census. ${ }^{39}$

\section{Individual variables}

Individual characteristics were included as covariates that had been found to be predictors of neighbourhood scale in previous studies. ${ }^{19} 25$ These characteristics included the following: gender, age (in years), employment status, length of residence in home (in years), presence of children under 10 years of age in the household, number of relatives in the same neighbourhood (none to all), number of people who pass in front of participants' houses who are known to them (none to all) and a composite indicator named the National Economic Index (NEI), which depicts the current socioeconomic position of the individual, ${ }^{40}$ based on consumer goods instead of income.

\section{Statistical analyses}

A descriptive analysis was carried out, followed by an analysis of the association between size of the neighbourhood scale and contextual features estimated by a multilevel ordinal logistic regression model. The first level consisted of the individual-level variables, and the second level consisted of the neighbourhood-level variables.

A regression model with random intercepts with a logit function were used to estimate the OR and the CI $(95 \% \mathrm{CI}) .{ }^{41}$ The median values of the OR (MOR) and the percentage of variance reduction were calculated. The Akaike information criterion (AIC) was used to compare models, with the model with the lowest AIC selected as the best model. ${ }^{42}$

First, a null model (only the random intercept) was estimated to assess the contextual effect, and then a univariate analysis was performed with a multilevel ordinal logistic regression for each of the contextual variables. Second, independent domains with a coefficient that was significant at $\mathrm{p}<0.20$ (aesthetic quality, walking environment, violence domain and safety) in the univariate analysis were included as level 2 variables in the multiple analysis. Finally, we added the individual characteristics (age, gender, employment status, number of parents and friends in the neighbourhood, recognition of people passing by the door of your house, length of residence in the same neighbourhood, presence of children younger than 10 and socioeconomic position) at level 1 for adjustment.

The analyses were performed in the software STATA V.12.0 (Stata Corp., College Station, Texas, USA). For all analyses, we used the svy command, ${ }^{43}$ which considers complex design and sampling weights. For all models, we considered a significance level of $5 \%$.

\section{Patient and public involvement}

The research participants were selected in two regions of the city that show great internal heterogeneity in relation to sociodemographic characteristics. The local population was previously informed about the objectives and importance of the research through several approaches, including the involvement of community leader representatives, religious groups, school educators and health agents of family and community health programmes. After the selection of the households, the objectives of the research were presented to each participant. The results of the study were thoroughly disseminated within the population and discussed with public policy administrators of the municipality.

\section{Ethical issues}

All participants provided informed consent.

\section{RESULTS}

The final sample had 4048 respondents, $53.1 \%$ of whom were men and $46.9 \%$ of whom were women, with ages varying between 18 and 95 years (mean $=44.4, \mathrm{SD}=16.9)$. We found that $57.8 \%$ of the participants considered their neighbourhood to extend from their own house to the end of the block, $23.3 \%$ considered their neighbourhood to be within the five closest blocks, $7.4 \%$ considered their neighbourhood to be within the nearest 10 blocks and $11.5 \%$ considered their neighbourhood to be larger than 10 blocks from their home (table 1 ).

There was a linear relationship between the size of the perceived neighbourhood and the time to walk to his/her end of the neighbourhood, with the following average times, in minutes, for each neighbourhood size stratum: 6.1, 13.5, 19.8 and 29.2.

The distribution of street connectivity was almost the same, with $39.7 \%$ of streets with connectivity between 0 and $3,24.8 \%$ with a value of 4 and $35.4 \%$ with values between 5 and 9 . The mean population density was 12264 
Table 1 Univariate analysis of individual variables by perceived neighbourhood scale: percentages, means and SD

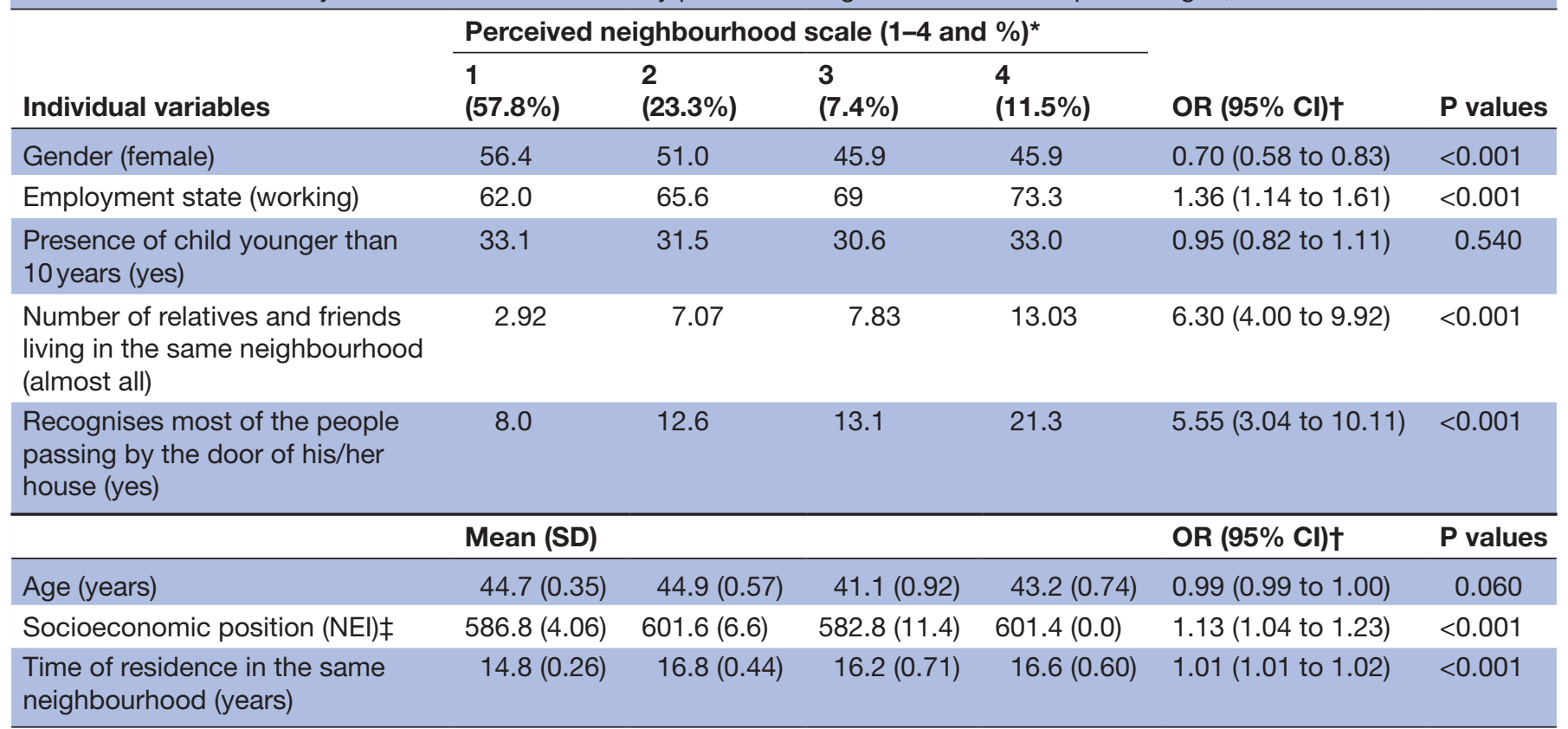

*(1) up to the block or street you live on; (2) within five blocks; (3) within 10 blocks; and (4) more than 10 blocks away. †Estimated by a multilevel ordinal logistic regression model, with reference category being the smaller neighbourhood. fOR calculated based on an increase of $200 \mathrm{NEI}$ points.

NEI, National Economic Index.

residents $/ \mathrm{km}^{2}$ (685.9). All of these results are shown in table 2.

The multilevel model analysis began with the null model. The perceived neighbourhood size had significant variation within the census tract, based on the likelihood ratio test $(\mathrm{p}<0.001)$. The analysis showed that the following domains and variables were significantly associated with self-perceived neighbourhood scale (table 3): walking environment (OR 2.96; 95\% CI 1.29 to 3.82), violence (OR 1.35; 95\% CI 1.12 to 1.62), female gender (OR $0.81 ; 95 \%$ CI 0.68 to 0.96 ), greater number of relatives living in the neighbourhood (OR 4.63; 95\% CI 2.84 to 7.57 ), recognition of more people in the neighbourhood (OR 3.33; 95\% CI 1.72 to 6.25 ) and socioeconomic position (NEI) (OR 1.17; 95\% CI 1.06 to 1.29).

Based on the AIC, the best models were adjusted by individual variables at level 1 . The median value of the OR comes from the median value between the area with

Table 2 Univariate analysis of contextual variables by perceived neighbourhood scale: percentages, means and SD

\begin{tabular}{|c|c|c|c|c|c|c|}
\hline \multirow[b]{2}{*}{ Contextual variables } & \multicolumn{4}{|c|}{ Neighbourhood extension scale (1-4 and \%)* } & \multirow[b]{2}{*}{ OR $(95 \% \mathrm{Cl}) \dagger$} & \multirow[b]{2}{*}{$P$ values } \\
\hline & $\begin{array}{l}1 \\
(57.8 \%)\end{array}$ & $\begin{array}{l}2 \\
(23.3 \%)\end{array}$ & $\begin{array}{l}3 \\
(7.4 \%)\end{array}$ & $\begin{array}{l}4 \\
(11.5 \%)\end{array}$ & & \\
\hline \multicolumn{7}{|l|}{ Connectivity $\ddagger$} \\
\hline 0 to 3 & 39.91 & 40.91 & 41.87 & 40.37 & 1.00 & \\
\hline 4 & 23.92 & 23.42 & 36.11 & 25.28 & 1.04 (0.83 to 1.30$)$ & 0.760 \\
\hline \multirow[t]{2}{*}{5 to 9} & 37.17 & 35.63 & 22.02 & 34.34 & 0.85 (0.70 to 1.04$)$ & 0.120 \\
\hline & Mean (SD) & & & & OR $(95 \% \mathrm{Cl}) \dagger$ & $P$ values \\
\hline Aesthetic quality domain & $2.96(0.03)$ & $3.07(0.04)$ & $3.06(0.07)$ & $3.09(0.04)$ & $1.23(1.03$ to 1.46$)$ & 0.020 \\
\hline Walking environment domain & $3.20(0.01)$ & $3.24(0.02)$ & $3.27(0.02)$ & $3.28(0.02)$ & 3.37 (2.09 to 5.44$)$ & $<0.001$ \\
\hline Violence scale domain & $1.90(0.02)$ & $1.95(0.03)$ & $1.89(0.05)$ & $2.00(0.04)$ & $1.20(1.03$ to 1.40$)$ & 0.020 \\
\hline Safety scale domain & $2.96(0.03)$ & $2.93(0.05)$ & $2.89(0.09)$ & $2.86(0.05)$ & $0.92(0.79$ to 1.08$)$ & 0.190 \\
\hline $\begin{array}{l}\text { Population density (per } \\
\text { square kilometre) }\end{array}$ & $\begin{array}{l}12487.35 \\
(791.26)\end{array}$ & $\begin{array}{l}11740.34 \\
(704.83)\end{array}$ & $\begin{array}{l}12274.31 \\
(740.63)\end{array}$ & $\begin{array}{l}12627.22 \\
(865.05)\end{array}$ & 1.00 (0.99 to 1.01$)$ & 0.650 \\
\hline
\end{tabular}

*(1) up to the block or street you live on; (2) within five blocks; (3) within 10 blocks; and (4) more than 10 blocks away. †Estimated by a multilevel ordinal logistic regression model, with reference category being the smaller neighbourhood. $\ddagger$ Zero indicates poorly connected streets and nine indicates heavily connected streets. 
Table 3 Multilevel ordinal logistic regression for the resident perceived neighbourhood scale

\begin{tabular}{|c|c|c|c|c|c|c|c|}
\hline \multirow[b]{2}{*}{ Variables } & \multirow{2}{*}{$\begin{array}{l}\text { Null } \\
\text { model }\end{array}$} & \multicolumn{3}{|c|}{ Contextual variables } & \multicolumn{3}{|c|}{$\begin{array}{l}\text { Contextual variables+individual } \\
\text { variables }\end{array}$} \\
\hline & & OR $(95 \% \mathrm{Cl})^{\star}$ & & $P$ values & OR $(95 \% \mathrm{Cl})^{*}$ & & $P$ values \\
\hline Aesthetic quality domain & & 1.21 (0.97 to 1.41$)$ & & 0.060 & $1.13(0.92$ to 1.39$)$ & & 0.230 \\
\hline Walking environment domain & & 2.96 (1.71 to 5.13$)$ & & $<0.001$ & 2.22 (1.29 to 3.82$)$ & & $<0.001$ \\
\hline Violence domain & & 1.35 (1.12 to 1.62$)$ & & $<0.001$ & $1.23(1.01$ to 1.51$)$ & & 0.040 \\
\hline Safety domain & & 0.97 (0.82 to 1.14$)$ & & 0.710 & 0.99 (0.83 to 1.19$)$ & & 0.950 \\
\hline \multicolumn{8}{|l|}{ Connectivity $†$} \\
\hline 4 & & 1.00 (0.80 to 1.26$)$ & & 0.940 & 1.06 (0.85 to 1.34$)$ & & 0.570 \\
\hline 5 to 9 & & 0.82 (0.67 to 1.01$)$ & & 0.060 & 0.89 (0.72 to 1.11$)$ & & 0.310 \\
\hline \multicolumn{8}{|l|}{ Individual } \\
\hline Age (years) & & & & & 1.00 (0.99 to 1.00$)$ & & 0.350 \\
\hline Gender (female) & & & & & 0.81 (0.68 to 0.96$)$ & & 0.020 \\
\hline $\begin{array}{l}\text { Number of relatives and } \\
\text { friends living in the same } \\
\text { neighbourhood (almost all) }\end{array}$ & & & & & $4.63(2.84$ to 7.57$)$ & & $<0.001$ \\
\hline $\begin{array}{l}\text { Recognises most of the } \\
\text { people passing by his/her } \\
\text { house (yes) }\end{array}$ & & & & & 3.33 (1.72 to 6.25$)$ & & $<0.001$ \\
\hline Employment state (working) & & & & & $1.26(1.06$ to 1.50$)$ & & 0.010 \\
\hline $\begin{array}{l}\text { Time of residence in the } \\
\text { same neighbourhood (years) }\end{array}$ & & & & & 1.01 (1.00 to 1.01$)$ & & 0.130 \\
\hline $\begin{array}{l}\text { Presence of child younger } \\
\text { than } 10 \text { years old (yes) }\end{array}$ & & & & & 0.97 (0.81 to 1.16$)$ & & 0.740 \\
\hline Socioeconomic positionł & & & & & 1.17 (1.06 to 1.29$)$ & & $<0.001$ \\
\hline \multicolumn{8}{|l|}{ Model information } \\
\hline Variance & 0.2567 & & 0.2292 & & & 0.2336 & \\
\hline MOR & 1.62 & & 1.58 & & & 1.58 & \\
\hline $\begin{array}{l}\text { Proportional change in } \\
\text { variance }\end{array}$ & - & & 10.71 & & & 9.00 & \\
\hline $\mathrm{AlC}$ & 8749.26 & & 8668.44 & & & 8091.83 & \\
\hline
\end{tabular}

*Estimated by a multilevel ordinal logistic regression model, with the reference category being the smaller neighbourhood.

†Zero indicates less connected streets and nine indicates heavily connected streets.

$\ddagger O R$ calculated based on an increase of 200 NEl points.

AIC, Akaike information criterion; MOR, median values of the OR; NEI, National Economic Index.

the highest odds of a larger perceived neighbourhood scale and the area with the lowest odds when randomly selecting two areas. ${ }^{41}$ We found an MOR of 1.62 for the null model, 1.58 for the model with the contextual predictors and 1.58 for the model adjusted by the individual variables. The results of the proportional change in variance show that the contextual predictors explained $10.7 \%$ of the total variance, and the model with contextual and individual variables explained $9.0 \%$. Although the best model based on the AIC is the model with contextual and individual variables, the model with only contextual variables has more variation than the null model. This finding indicates that $10.0 \%$ of the contextual variance of perceived neighbourhood scale was attributed to the contextual factors and that when we added the individual-level variables, it decreased slightly to $9.0 \%$ (table 3 ).

\section{DISCUSSION}

Perceived neighbourhood scale was relatively small for many residents: $57.8 \%$ of the participants considered their neighbourhood to be residences closest to their home until the end of the block. Additionally, contextual factors, such as perceived quality of environmental conditions for walking and indicators of a violent environment, were associated with a larger perceived neighbourhood scale, even adjusted by individual-level variables.

These findings allow for comparison with those of previous studies, but care must be taken because each study has different approaches in measuring perceived neighbourhood. A study carried out in the city of Los Angeles ${ }^{44}$ reported that $35.1 \%$ of the interviewees considered their neighbourhood the block or street that they live on, $25.0 \%$ several blocks or streets in each direction, 
$28.8 \%$ an area within a 15 min walk and $13.1 \%$ an area larger than a 15 min walk. In other words, $86.9 \%$ of participants considered their neighbourhood an area smaller than a 15 min walk. This result is very similar to what we found; when we look at the average time taken to leave the self-perceived neighbourhood within each stratum, $81.1 \%$ of participants considered their neighbourhood an area smaller than a 15 min walk.

Another study conducted in different areas of Seattle ${ }^{23}$ found that $46.4 \%$ of participants considered their neighbourhood to extend from their own residential unit to no more than one block in each direction.

However, studies using maps as an approach to measure the perceived neighbourhood found much larger neighbourhoods. A study ${ }^{22}$ conducted in five European urban regions found a mean perceived neighbourhood of $1.96 \mathrm{~km}^{2}$. Similar results were found in a small study conducted with adolescents in Boston, where a mean area of $1.82 \mathrm{~km}^{2}$ was reported. In a pilot study conducted in Auckland (New Zealand), Stewart et $a l^{45}$ found a perceived neighbourhood area of $3.54 \mathrm{~km}^{2}$; in a study with 6224 adults in low-income communities in 10 US cities, Coulton et $a l^{19}$ found an area of $2.33 \mathrm{~km}^{2}$. A study conducted with 15982 persons, in Helsinki and Espoo, Finland, that calculated the area inside the most visited points in a neighbourhood found an average area of $1.07 \mathrm{~km}^{2}{ }^{46}$

Despite the heterogeneities in the sampling and methods used among studies, studies that used maps found larger neighbourhoods, indicating a possible relationship with the methodology used to access the perceived neighbourhood. A possible explanation is that it is easier to remember important points in neighbourhoods when participants look at a map. Using an openended or closed-ended question does not provide that kind of specific context.

The results of the multilevel model show us that there are contextual factors associated with perceived neighbourhood scale. We found associations with the perceptions of the walking environment and with violence. The interpretation of the results of the domains should be performed based on the analysis of the behaviour of its score. ${ }^{36}$ The walking environment domain had highest values when the census tract had more people who reported that their neighbourhoods have a physical environment that encourages mobility and external activities. To our knowledge, the literature does not report a similar relationship, but it is plausible that an area that stimulates the mobility of people, facilitating diverse activities within the neighbourhood, could also be related to a large perceived neighbourhood scale.

The violence domain, which reports higher values for more violent neighbourhoods, was associated with larger perceived neighbourhood scale. This finding appears to be contradictory at first glance, but people with larger perceived neighbourhoods are likely to have greater social contact and exposure to the environment and may therefore be able to identify the problems within the neighbourhood.
Regarding connectivity, we found an association between high street connectivity and larger perceived neighbourhood scale only in a univariate analysis, despite a negative association found in another publication. ${ }^{19}$ After adjustments, connectivity was no longer significant, although the plausibility of the association remains; highly connected streets tend to be located in busier places with a high demographic density and intense automobile traffic, which hampers social contact and favours less extensive perceptions.

Demographic density was not associated with neighbourhood perception. The literature consulted differs in relation to this variable. Some studies have found ${ }^{1921}$ an association between smaller perceived neighbourhood and greater population density. Others have reported an association between higher population densities and larger neighbourhoods, ${ }^{22} 47$ and yet other studies, such ours, have found no relationship. ${ }^{24}{ }^{44}$ However, neighbourhoods with a high population density, especially if car traffic is intense, could also have impoverished social contact among neighbours, favouring a lower neighbourhood perception, in the same direction of connectivity.

This study has specific limitations that need to be mentioned. First, the use of a closed-ended question to obtain the perceived neighbourhood scale does not specify the spaces to which individuals are actually exposed. Second, the cross-sectional design of the study limits the interpretation of some results due to the possibility of reverse causality. Third, the results of this study are from a large urban centre and are not necessarily valid for smaller cities and rural areas. Fourth, the findings may not apply to children, since individuals younger than 18 years were not included in this study.

The identification of the contextual factors associated with the perception of neighbourhood scale have important methodological implications, especially for studies that intend to investigate the association between social factors of the neighbourhood and health events. The perceived neighbourhood scale is a fundamental tool for the creation of more precise and coherent neighbourhood boundaries informed by the places actually experienced by individuals.

One of the motivations of this study is related to the fact that a large amount of research in eco-epidemiology and community practice tends to use artificial definitions of neighbourhoods' boundaries. The results of this study demonstrate that there is heterogeneity among residents on their perceived neighbourhood scale, reinforcing the argument that researchers need to use more personalised ways to define neighbourhood boundaries. Most research uses census tracts as a proxy for neighbourhoods due to the availability of data aggregated at this level, but the increased use of geographic information system techniques supports more individualised neighbourhood definitions that can be used to avoid problems regarding the choice of neighbourhood size and its operationalisation. A more carefully defined 
neighbourhood unit will help future eco-epidemiological studies to produce evidence to support community practices.

Contributors FAC: participated in the design of the study and its conception; was responsible for writing the article and the following activities: setting up the database, performing the statistical analysis, reviewing the text and approving the final version. AALF: participated in the design of the field work, reviewed all versions of the paper, ensured its accuracy and integrity and approved the final version. MZJ: participated in design, ensured the accuracy and integrity of the data and approved the versions of the paper and the final version. ACSA: participated in the design of the work, reviewed all versions, performed the statistical analysis, ensured the accuracy and precision of the data and approved the final version of the paper. CCX: participated in the design of the field work and approved the final version of the paper. FAP: participated in the design of the field work and approved the final version of the paper. CJC: participated in the analysis of the paper and approved the final version. WTC: participated in the design and construction of the field work, reviewed all versions of the paper, ensured its accuracy and integrity and approved the final version.

Funding National Health Fund of the Ministry of Health, Fapemig, CNPq, NIH/ Fogarty International Centre.

Competing interests None declared.

Patient consent Obtained.

Ethics approval Research Ethics Committee of the UFMG ETIC $n^{\circ}$ 253/06.

Provenance and peer review Not commissioned; externally peer reviewed.

Data sharing statement All relevant data are within the paper. The data underlying this study are third-party data and are available to all interested researchers. To gain access to these data, please submit a proposal the OSUBH Coordinating Centre at http://site.medicina.ufmg.br/osubh/contato/.

Open access This is an open access article distributed in accordance with the Creative Commons Attribution Non Commercial (CC BY-NC 4.0) license, which permits others to distribute, remix, adapt, build upon this work non-commercially, and license their derivative works on different terms, provided the original work is properly cited, appropriate credit is given, any changes made indicated, and the use is non-commercial. See: http://creativecommons.org/licenses/by-nc/4.0/.

\section{REFERENCES}

1. Diez Roux AV. Health in cities: is a systems approach needed? Cad Saude Publica 2015;31(Suppl 1):9-13.

2. Cohen D, Spear S, Scribner R, et al. "Broken windows" and the risk of gonorrhea. Am J Public Health 2000;90:230.

3. Schaefer-McDaniel N, Caughy MO, O'Campo P, et al. Examining methodological details of neighbourhood observations and the relationship to health: a literature review. Soc Sci Med 2010;70:277-92.

4. Diez Roux AV, Mair C. Neighborhoods and health. Ann N Y Acad Sci 2010;1186:125-45.

5. Diez Roux AV, Merkin SS, Arnett D, et al. Neighborhood of residence and incidence of coronary heart disease. N Engl J Med 2001;345:99-106.

6. Mair C, Diez Roux AV, Galea S. Are neighborhood characteristics associated with depressive symptoms? A critical review. Journal of Epidemiology \& Community Health 2008:jech. 2007.066605.

7. ACdS A, Peixoto SV, AAdL F, et al. Social context of neighborhood and socioeconomic status on leisure-time physical activity in a Brazilian urban center: The BH Health Study. Cadernos de Saúde Pública 2015;31:136-47.

8. Fernandes AP, Andrade ACdeS, Ramos CGC, et al. Leisure-time physical activity in the vicinity of academias da cidade program in belo horizonte, minas gerais state, brazil: the impact of a health promotion program on the community. Cadernos de Saúde Pública 2015;31:195-207.

9. Chaix B, Kestens $\mathrm{Y}$, Bean $\mathrm{K}$, et al. Cohort profile : residential and non-residential environments, individual activity spaces and cardiovascular risk factors and diseases-the RECORD Cohort Study. Int J Epidemiol 2012;41:1-10.

10. Ludwig J, Duncan GJ, Gennetian LA, et al. Neighborhood effects on the long-term well-being of low-income adults. Science 2012;337:1505-10.
11. Kaiser P, Diez Roux AV, Mujahid M, et al. Neighborhood environments and incident hypertension in the multi-ethnic study of atherosclerosis. Am J Epidemiol 2016;183:988-97.

12. Johnson DA, Simonelli G, Moore K, et al. The neighborhood social environment and objective measures of sleep in the multi-ethnic study of atherosclerosis. Sleep 2017;40.

13. Chaix B, Merlo J, Evans D, et al. Neighbourhoods in ecoepidemiologic research: delimiting personal exposure areas. A response to Riva, Gauvin, Apparicio and Brodeur. Soc Sci Med 2009;69:1306-10.

14. Flowerdew R, Manley DJ, Sabel CE. Neighbourhood effects on health: does it matter where you draw the boundaries? Soc Sci Med 2008;66:1241-55.

15. Galster G. On the Nature of Neighbourhood. Urban Stud 2001;38:2111-24.

16. Chaskin RJ. Perspectives on neighborhood and community: a review of the literature. Soc Serv Rev 1997;71:521-47.

17. Chappell NL, Funk LM, Allan D. Defining community boundaries in health promotion research. Am J Health Promot 2006;21:119-26.

18. Chaix B, Méline J, Duncan S, et al. GPS tracking in neighborhood and health studies: a step forward for environmental exposure assessment, a step backward for causal inference? Health Place 2013;21:46-51.

19. Coulton CJ, Jennings MZ, Chan T. How big is my neighborhood? Individual and contextual effects on perceptions of neighborhood scale. Am J Community Psychol 2013;51:1-11.

20. Coulton CJ, Korbin J, Chan T, et al. Mapping residents' perceptions of neighborhood boundaries: a methodological note. Am J Community Psychol 2001;29:371-83.

21. Haney WG, Knowles ES. Perception of neighborhoods by city and suburban residents. Hum Ecol 1978;6:201-14.

22. Charreire H, Feuillet T, Roda C, et al. Self-defined residential neighbourhoods: size variations and correlates across five European urban regions. Obes Rev 2016;17(Suppl 1):9-18.

23. Guest AM, Lee BA. How urbanites define their neighborhoods. Popul Environ 1984;7:32-56.

24. Pebley AR, Sastry N. Our place: perceived neighborhood size and names in Los Angeles. Los Angeles: California Center for Population Research, University of California, 2009.

25. FdA C, Xavier CC, ACdS A, et al. Características individuais associadas à autopercepção da extensão territorial da vizinhança. Cadernos de Saúde Pública 2014;30:1935-46.

26. Cutchin MP, Eschbach K, Mair CA, et al. The socio-spatial neighborhood estimation method: an approach to operationalizing the neighborhood concept. Health Place 2011;17:1113-21.

27. Fotheringham AS, Wong DWS. The modifiable areal unit problem in multivariate statistical analysis. Environment and Planning $A$ 1991;23:1025-44.

28. Duncan DT, Kawachi I, Subramanian SV, et al. Examination of how neighborhood definition influences measurements of youths access to tobacco retailers: a methodological note on spatial misclassification. Am J Epidemiol 2014;179.

29. Sampson RJ, Morenoff JD, Gannon-Rowley T. Assessing "neighborhood effects": social processes and new directions in research. Annu Rev Sociol 2002;28:443-78.

30. Hillier B. Spatial sustainability in cities: organic patterns and sustainable forms, 2009.

31. Andrade RG, Chaves OC, Costa DA, et al. Overweight in men and women among urban area residents: individual factors and socioeconomic context. Cad Saude Publica 2015;31(Suppl 1):148-58.

32. Camargos VP, César CC, Caiaffa WT, et al. Imputação múltipla e análise de casos completos em modelos de regressão logística: uma avaliação prática do impacto das perdas em covariáveis. Cadernos de Saúde Pública 2011;27:2299-313.

33. Ferreira AD, César CC, Malta DC, et al. Validade de estimativas obtidas por inquérito telefônico: comparação entre VIGITEL 2008 e inquérito Saúde em Beagá. Rev Bras Epidemiol 2011;14:16-30.

34. Secondary Índice de vulnerabilidade à saúde. Gerência de Epidemiologia e Informação Secretaria Municipal de Saúde de Belo Horizonte. Índice de vulnerabilidade à saúde. 2003 http://www.pbh. gov.br/smsa/biblioteca/gabinete/risco2003.

35. Friche AA, Xavier CC, Proietti FA, et al. Saúde urbana em Belo Horizote. 1st edn, 2015.

36. Friche AA, Diez-Roux AV, Cesar CC, et al. Assessing the psychometric and ecometric properties of neighborhood scales in. Journal of urban health: bulletin of the New York Academy of Medicine 2012.

37. Universiy of London. Dephmap [program]. 4.06 version, 2004.

38. Song $Y$, Knaap G-J. Measuring urban form: is portland winning the war on sprawl? J Am Plann Assoc 2004;70:210-25. 
39. Demográfico IC. Resultados do universo: Rio de Janeiro: IBGE, 2010.

40. Barros AJD, Victora CG. Indicador econômico para o Brasil baseado no censo demográfico de 2000. Revista de Saúde Pública 2005;39:523-9.

41. Merlo J, Chaix B, Ohlsson $\mathrm{H}$, et al. A brief conceptual tutorial of multilevel analysis in social epidemiology: using measures of clustering in multilevel logistic regression to investigate contextual phenomena. J Epidemiol Community Health 2006;60:290-7.

42. Twisk J. Applied multilevel analysis: a practical guide. Cambridge, UK: Cambridge University Press, 2006

43. StataCorp L. Stata survey data reference manual, 1985.
44. Sastry N, Pebley AR, Zonta M. Neighborhood definitions and the spatial dimension of daily life in Los Angeles. California Center for Population Research 2002.

45. Stewart T, Duncan S, Chaix B, et al. A novel assessment of adolescent mobility: a pilot study. Int J Behav Nutr Phys Act 2015;12:18.

46. Hasanzadeh $\mathrm{K}$, Broberg $\mathrm{A}$, Kyttä M. Where is my neighborhood? A dynamic individual-based definition of home ranges and implementation of multiple evaluation criteria. Appl Geogr 2017:84:1-10.

47. Vallée J, Le Roux G, Chaix B, et al. The 'constant size neighbourhood trap'in accessibility and health studies. Urban Studies 2014:0042098014528393. 